\title{
Design and Realization of Well Pattern Optimization Software
}

\author{
Chang Junhua, Zhang Jiqun, Li Xinhao, Xu Xiaoming, Li Hua \\ Software Research Center of Oil \& Gas Development \\ PetroChina Research Institute of Petroleum Exploration and Development \\ Beijing, China \\ \{cjhren,zhangjiq,lixinhao,xxiaom,lihua001\}@petrochina.com.cn
}

\begin{abstract}
This paper provides a kind of computer assisted well pattern optimization design technology and its software realization method. Based on the requirements on well pattern arrangement and adjustment for secondary development of mature oil fields, virtual well locations were arranged for multiple types of well patterns, different well spacing and various well alignment directions, and well patterns were adjusted according to oil reservoir configurations and source directions. Based on the grid attribute values of oil and water well locations and their relationships with the boundary of reservoir sand bodies, oil and water well points were adjusted by making full use of old wells. Indexes (e.g. oil and water well drilling ratio and drilled layer amount) were calculated to the well locations of the finally generated new well patterns, and numerical reservoir simulation input file format was output automatically. Development indexes (e.g. recovery factor and water cut) were predicted fast. In this way, it is conductive for reservoir engineers to optimize well patterns and well spacing fast. The well pattern optimization software which was designed considering above mentioned technical methods was applied to the secondary development plans and development adjustment plans of over 10 oil reservoir blocks in mature oil fields with high water cut, and the working efficiency and study precision are increased greatly.
\end{abstract}

Keywords-areal pattern; optimization design; grid interpolation; index calculation; secondary development

\section{INTRODUCTION}

In China, casing deformation and damage are serious in producers and injectors, injection-production systems are not complete and water flooding control degree is low, when onshore mature oil fields are at the development stage with high water cut. Therefore, PetroChina adopted new concepts and technical approaches to rebuild underground cognition systems, delineate single sand body accurately and describe remaining oil precisely. Then, oil reservoirs are improved in terms of producing degree by subdividing and recombining the layers vertically, and injection-production relationship is improved and water flooding control degree is increased by optimizing and adjusting well patterns areally. In this way, the recovery factor of water flooding development is ultimately increased.

In recent years, numerous achievements have been obtained in aspects of pattern optimization adjustment plans and infilling plans for special types of oil reservoirs [2-5]. However, no literatures have ever presented general well pattern optimization technology and software which are used to select the optimal one from multiple well pattern plans which are designed on the basis of pattern types, well spacing and well types comprehensively.

In the process of well pattern optimization design, it is necessary to arrange virtual well locations for multiple types of well patterns, different well spacing and various well alignment directions and calculate the related parameters, so as to conduct optimization and comparison on multiple examples and eventually put forward rational, economic and efficient well pattern arrangement plan and well location coordinates. This process is quite time and effort consuming. In this paper, therefore, computer technology is used to perform interpolation calculation on well layers in terms of static physical properties and fluid attributes. Based on the spatial distribution of reservoir and fluid attributes, automatic computer arrangement is completed by using multiple types of areal patterns, well spacing and well alignment directions which are set by reservoir engineers, and the related parameters (e.g. single-well oil reservoir drilling ratio) are calculated. Then, software systems are worked out, by which, layer data sheets are automatically generated for new well patterns, including well location coordinates, well layer thickness, and remaining oil saturation. It is conductive for reservoir engineers to predict recovery factor fast by using numerical reservoir simulation software or other reservoir engineering software.

\section{WELL PATTERN ARRANGEMENT TECHNOLOGY}

In order to complete well pattern optimization design, it is necessary to take into consideration the sand body morphology, oil bearing area, fault strike, controlled reserves and remaining oil distribution. Moreover, the well pattern types, well spacing and well types are considered to realize maximization of drilling ratio, water flooding control degree, recovery factor and economic benefit.

The design flow of computer automatic arrangement is mainly as follows.

1) Read the data volume of reservoir physical properties and fluid attributes and the information of old wells. 
2) If only well point parameter information is available, use the equal distance weighted and Kriging interpolation for interpolation calculation to obtain interwell attributes.

3) Based on reservoir engineering combined with economic evaluation principle, calculate economically optimal well pattern density and determine the range of well spacing preliminarily.

4) Arrange areal well patterns with different pattern types and well spacing on each oil reservoir overlay chart.

5) Carry out overall adjustment on well patterns based on oil reservoir dipping, fault distribution and reservoir sand boundary trend.

6) Confirm whether to keep the well point or change its location based on its attributes (e.g. effective thickness, porosity and oil saturation) and the situations of its peripheral old wells.

7) Calculate the indexes of the new well patterns, including the quantity of producers and injectors in each oil reservoir, single-well layer dynamic and static attributes, and single-well drilling thickness and number of layers.

8) Output the numerical simulation input data files automatically in the specified forms, to help reservoir engineers predict other indexes (e.g. recovery factor) fast.

\section{A. Computer arrangement technology for areal well patterns}

In areal water flooding patterns, water injectors and oil producers are distributed uniformly in a certain form in the whole oil field. Based on the ratio between water injectors and oil producers and their configurations, these patterns are classified as five-spot pattern (Fig.1), inverted nine-spot pattern (Fig.2) and four-spot pattern (Fig.3).

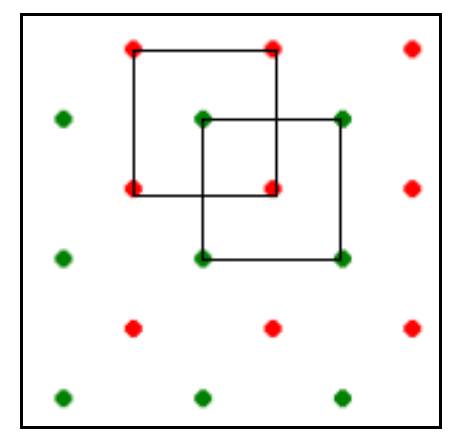

Fig. 1. Five-spot pattern

According to the concept of areal well pattern arrangement, oil producers and water injectors are uniformly arranged with a certain well spacing in one rectangular area. Next, the way to arrange a five-spot areal well pattern is described.

The rectangular area is divided equally into four quadrants, and a five-spot pattern is arranged in the first quadrant. Firstly, water injectors are arranged. The first water injector is located in the center and the other water injectors are separated with one well spacing along $\mathrm{X}$ and $\mathrm{Y}$ directions. Then, oil producers are arranged in turn in the first quadrant. Five-spot patterns are symmetric, so the well patterns in the other three quadrants can be arranged one by one on the basis of image reflection after the first quadrant is arranged (Fig.4).

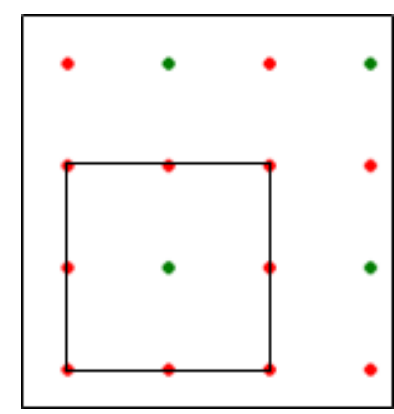

Fig. 2. Inverted nine-spot pattern

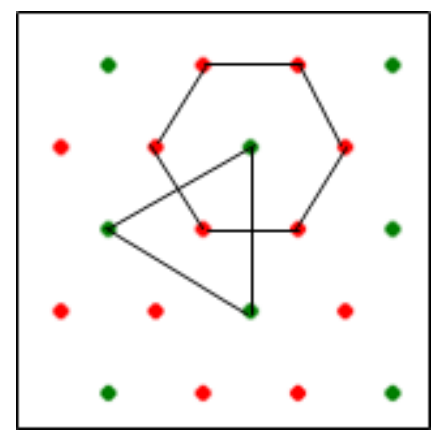

Fig. 3. Four-spot pattern

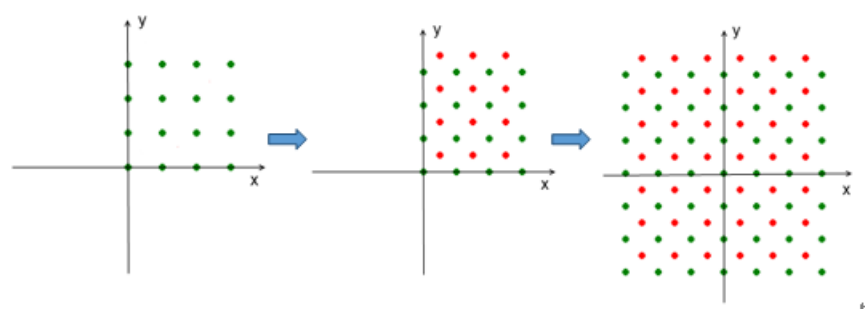

Fig. 4. The arrangement process of areal well patterns

Four-spot and inverted nine-spot well patterns are also symmetric, so they can be arranged in the same way.

\section{B. Attribute determination of well points in the new well patterns}

After areal well patterns are arranged on the areal map of oil reservoirs, it is necessary to learn attribute values of each well point, including effective thickness, porosity, permeability, oil saturation and so on. These attribute values can be obtained by means of two methods. The first is to read directly the grid attribute interpolation results from the third party's software, such as the attribute data volumes of numerical simulation or 
modeling. The second is to perform areal grid interpolation based on single-well layer data sheet of old well patterns, oil bearing areas and sandbody boundaries. The second method is illustrated in detail below.

The commonly used grid interpolation methods include Inverse Distance Weighted (IDW), Kriging interpolation, Radial Basis Function (RBF), Delaunay triangulation interpolation and Shepard interpolation.

Here, IDW is taken as an example for illustration. In principle, the closer two objects are, the more similar their properties are, and vice versa. The distance between interpolation points and sample points are taken as the weight for weighted average. The closer the sample points are to interpolation points, the weight on sample points are higher.

The general formula for IDW is as follows:

$$
\hat{\mathrm{Z}}\left(\mathrm{S}_{0}\right)=\sum_{\mathrm{i}=1}^{\mathrm{N}} \lambda_{\mathrm{i}} Z\left(S_{i}\right)
$$

Where, $\widehat{\mathrm{Z}}\left(\mathrm{S}_{0}\right)$ is the predicted value at the point of $S_{0}, \mathrm{~N}$ is the amount of sample points around prediction point which is used for prediction calculation, $\lambda_{i}$ is the weight of all sample points which are used for prediction calculation and it decreases with the increasing of the distance between sample points and prediction points, and $\mathrm{Z}\left(\mathrm{S}_{\mathrm{i}}\right)$ is the measured value at $S_{i}$. The calculation formula to determine weights is as follows.

$$
\lambda_{i}=\frac{d_{i D}^{-D}}{\sum_{i=1}^{N} d_{i 0}^{-D}}, \quad \sum_{i=1}^{N} \lambda_{i}=1
$$

Where, $p$ is a numerical value, generally set at $2, d_{i 0}$ is the distance between the prediction point $S_{0}$ and the given sample point $S_{i}$. Weights of sample points and prediction points in calculation are influenced by $\mathrm{P}$. It means that weight of the effect of standard sample points on prediction points decreases in accordance with exponent laws with the increase of the distance between sample points and perdition points. In the process of prediction, the weights of the effect of sample points on prediction points are proportional, and the sum of the weights is 1 .

When grid interpolation is conducted on layer attributes by using layer data sheet of old wells, attention shall be paid to the boundary relationships and attribute differences. For example, effective thickness and oil saturation are not 0 within the boundary of oil bearing area, but 0 outside it. Permeability and sandstone thickness, however, are not 0 within the boundary of the whole sandstones.

\section{Well alignment direction and local well point adjustment method}

After basic well patterns are arranged, it is necessary to adjust well alignment directions and local well points depending on the configuration and material source directions of oil reservoirs. Importantly, old wells shall be used if possible. In the areas with incomplete injection and production configurations (e.g. without producer or injector), it is necessary add or remove wells as the case maybe. Sometimes, water injectors should be added near edge water to supplement energy.
Well pattern adjustment include translation (up, down, left and right) and rotation (counter clockwise and clockwise) of the whole well pattern and local well points, adding and removal of well points, and well type change of selected wells (conversion of oil producer and water injector). It can be valid for all layers (layer superimposition) or several layers.

Translation:

$$
\mathrm{X}^{\prime}=\mathrm{X}+\Delta \mathrm{X}, \quad \mathrm{Y}^{\prime}=\mathrm{Y}+\Delta \mathrm{Y}
$$

Where, $\mathrm{X}^{\prime}$ and $\mathrm{Y}^{\prime}$ are the coordinates after the adjustment, $\mathrm{X}$ and $\mathrm{Y}$ are the original coordinates, $\Delta \mathrm{X}$ and $\Delta \mathrm{Y}$ are translation distance. If $\Delta \mathrm{X}$ and $\Delta \mathrm{Y}$ are negative, it means reverse translation.

Rotation:

$$
\mathrm{X}^{\prime}=\mathrm{X} \cos \theta-\mathrm{Y} \sin \theta, \quad \mathrm{Y}^{\prime}=\mathrm{Y} \sin \theta+\mathrm{Y} \cos \theta
$$

Where, $\theta$ is the rotation angle, ${ }^{\circ}$. If it is positive (negative), it means counterclockwise (clockwise) rotation.

Through overall translation and rotation of well patterns, well alignment directions can adapt to the faults and boundaries of oil reservoirs and accord with material source directions of oil reservoirs.

Well point adding: Add one oil producer (or water injector) at the specified location.

Well point removal: Select and then remove certain well(s). Well removal means no perforation at this layer in this well.

Well type change: Change well types of the selected wells, i.e. convert oil producer (water injector) into water injector (oil producer).

\section{Index calculation and result output}

Well pattern evaluation indexes are calculated for each well pattern arrangement plan. Based on index comparison, the advantages and disadvantages of the plan are preliminarily identified. Such indexes include number of oil producers and water injectors, producer/injector ratio, number and thickness of layers drilled by producers/injectors, drilling ratio and etc. Besides, well location information of well patterns and layer data sheet of new well patterns are output (TABLE I. ).

\section{TABLE I. LAYER DATA (SAMPLE)}

\begin{tabular}{|c|c|c|c|c|c|c|c|c|}
\hline $\begin{array}{c}\text { Well } \\
\text { No. }\end{array}$ & $\begin{array}{c}\text { Nayer } \\
\text { No. }\end{array}$ & $\begin{array}{c}\text { Coordi } \\
\text { nate }\end{array}$ & $\begin{array}{c}\text { Y } \\
\text { coordi } \\
\text { nate }\end{array}$ & $\begin{array}{c}\text { Effective } \\
\text { thickness }\end{array}$ & $\begin{array}{c}\text { Poro } \\
\text { sity }\end{array}$ & $\begin{array}{c}\text { Permeabi } \\
\text { lity }\end{array}$ & $\begin{array}{c}\text { Oil } \\
\text { saturati } \\
\text { on }\end{array}$ & $\begin{array}{c}\text { Sandstone } \\
\text { thickness }\end{array}$ \\
\hline$\ldots$ & $\ldots$ & $\ldots$ & $\ldots$ & $\ldots$ & $\ldots$ & $\ldots$ & $\ldots$ & $\ldots$ \\
\hline
\end{tabular}

TABLE II. STATISTICS OF PRODUCERS AND INJECTORS (SAMPLE)

\begin{tabular}{|c|c|c|c|}
\hline Layer No. & $\begin{array}{c}\text { Number of } \\
\text { producers }\end{array}$ & $\begin{array}{c}\text { Number of } \\
\text { injectors }\end{array}$ & $\begin{array}{c}\text { Producer/injecto } \\
\text { r ratio }\end{array}$ \\
\hline$\ldots$ & $\ldots$ & $\ldots$ & $\ldots$ \\
\hline
\end{tabular}

The number of producers and injectors and producer/injector ratio are collected for each layer (TABLE II. ). 
The index statistics of each well are shown in TABLE III. and TABLE IV. , including drilling thickness, number of layers drilled, drilling thickness ratio and drilled layer ratio.

TABLE III. STATISTICS OF DRILLING THICKNESS AND NUMBER OF LAYERS OF WELLS (SAMPLE)

\begin{tabular}{|c|c|c|c|c|c|}
\hline $\begin{array}{c}\text { Well } \\
\text { No. }\end{array}$ & $\begin{array}{c}\text { Well } \\
\text { type }\end{array}$ & $\begin{array}{c}\text { Drilling } \\
\text { thickness }\end{array}$ & $\begin{array}{c}\text { Number } \\
\text { of layers } \\
\text { drilled }\end{array}$ & $\begin{array}{c}\text { Drilling } \\
\text { thickness } \\
\text { ratio }\end{array}$ & $\begin{array}{c}\text { Drilled layer } \\
\text { ratio }\end{array}$ \\
\hline$\ldots$ & $\ldots$ & $\ldots$ & $\ldots$ & $\ldots$ & $\ldots$ \\
\hline
\end{tabular}

TABLE IV. STATISTICS OF AVERAGE DRILLING THICKNESS AND NUMBER OF LAYERS (SAMPLE)

\begin{tabular}{|c|c|c|c|c|}
\hline & $\begin{array}{c}\text { Drilling } \\
\text { thickness }\end{array}$ & $\begin{array}{c}\text { Number of } \\
\text { layers drilled }\end{array}$ & $\begin{array}{c}\text { Drilled layer } \\
\text { ratio }\end{array}$ & $\begin{array}{c}\text { Drilling thickness } \\
\text { ratio }\end{array}$ \\
\hline $\begin{array}{c}\text { Producers } \\
\text { (avg.) }\end{array}$ & $\ldots$ & $\ldots$ & $\ldots$ & $\ldots$ \\
\hline $\begin{array}{c}\text { Injectors } \\
\text { (avg.) }\end{array}$ & $\cdots$ & $\ldots$ & $\ldots$ & $\ldots$ \\
\hline $\begin{array}{c}\text { All wells } \\
\text { (avg.) }\end{array}$ & $\cdots$ & $\ldots$ & $\ldots$ & $\ldots$ \\
\hline
\end{tabular}

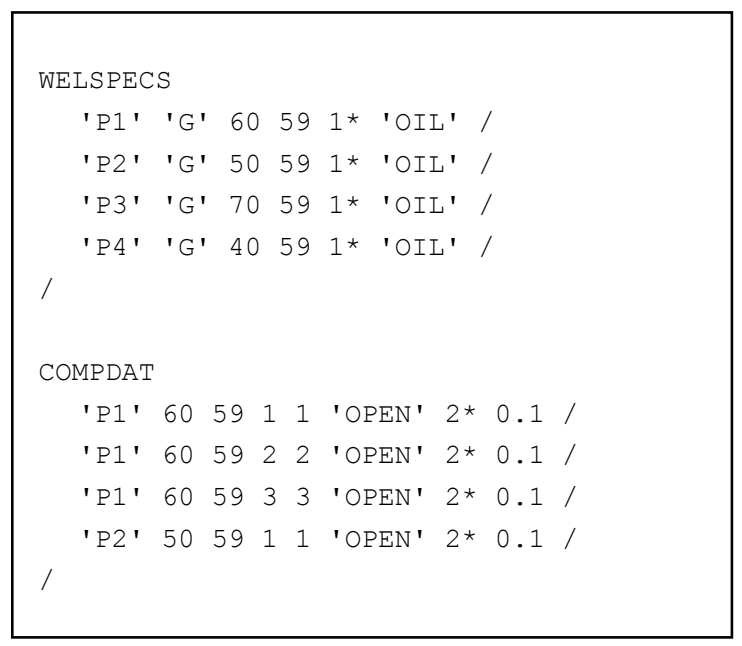

Fig. 5. Output file format for eclipse(sample)

Numerical simulation software shall be connected if index prediction is conducted on the new well patterns. Therefore, it is necessary to output well location coordinates according to the requirements of numerical simulation software. As for eclipse numerical simulation software, the data corresponding to the two keywords WELSPECS and COMPDAT shall be output, see Fig. 5.

\section{REALIZATION OF THE SOFTWARE}

Based on above mentioned well pattern arrangement technology, well pattern optimization software is compiled with the popular C\# programming language. In the software, the open-source control SharpMap acts as the graphic display system. Layer management is adopted for graphic elements, such as old wells, boundaries, new wells, and etc. The interface of the software is designed in the style of Windows interface, and its menus and shortcut keys are in accordance with operation conventions of Windows standard applications, so it can be operated simply and directly.

Its main functions are as follows.

- Arrange areal well patterns, including five-spot, inverted nine-spot, four-spot, diamond shaped five-spot and diamond shaped inverted nine-spot patterns.

- Realize grid interpolation algorithms, including IDW, Kriging, RBF, Delaunay and Shepard.

- Implement well pattern translation (up, down, left and right) and rotation (clockwise and counterclockwise), and realize selection of well points and perform translation, rotation and deletion on the selected well points.

- Perform Undo and Redo functions to well pattern adjustment.These functions can be realized by using Command mode.

- Fulfill statistics and calculation of well pattern indexes, including the statistics of producers and injectors in each layer and the calculation of drilling ratio. The calculation results can be output into excel sheets.

\section{APPLICATION OF THE SOFTWARE}

During the secondary development of PetroChina's block in an oilfield in eastern China, multiple virtual well patterns should be arranged to select the optimal one. After fine reservoir study, 12 virtual well patterns were designed in terms of pattern types, well spacing and well types.

TABLE V. DESIGN OF LAYER RECOMBINATION OPTIMIZATION PLANS FOR DIFFERENT WELL PATTERNS

\begin{tabular}{|c|c|c|c|}
\hline Plan No. & $\begin{array}{c}\text { Well pattern } \\
\text { type }\end{array}$ & Well spacing & Well type \\
\hline 1 & Triangular & $120 \mathrm{~m}$ & Vertical \\
\hline 2 & Triangular & $160 \mathrm{~m}$ & Vertical \\
\hline 3 & Triangular & $200 \mathrm{~m}$ & Vertical \\
\hline 4 & Five-spot & $120 \mathrm{~m}$ & Vertical \\
\hline 5 & Five-spot & $160 \mathrm{~m}$ & Vertical \\
\hline 6 & Five-spot & $200 \mathrm{~m}$ & Vertical \\
\hline 7 & Triangular & $120 \mathrm{~m}$ & Deviated \\
\hline 8 & Triangular & $160 \mathrm{~m}$ & Deviated \\
\hline 9 & Triangular & $200 \mathrm{~m}$ & Deviated \\
\hline 10 & Five-spot & $120 \mathrm{~m}$ & Deviated \\
\hline 11 & Five-spot & $160 \mathrm{~m}$ & Deviated \\
\hline 12 & Five-spot & $200 \mathrm{~m}$ & Deviated \\
\hline
\end{tabular}

There were two types of well patterns, i.e. triangular pattern and five-spot pattern. The well spacing was $120 \mathrm{~m}, 160 \mathrm{~m}$ and $200 \mathrm{~m}$. There were two well types, including vertical and deviated wells. The parameters of the plans are shown in TABLE V. Above 12 candidate well patterns were arranged and analyzed by the software. Indexes were collected for each plan, including producer drilling ratio and number of producers/injectors. 


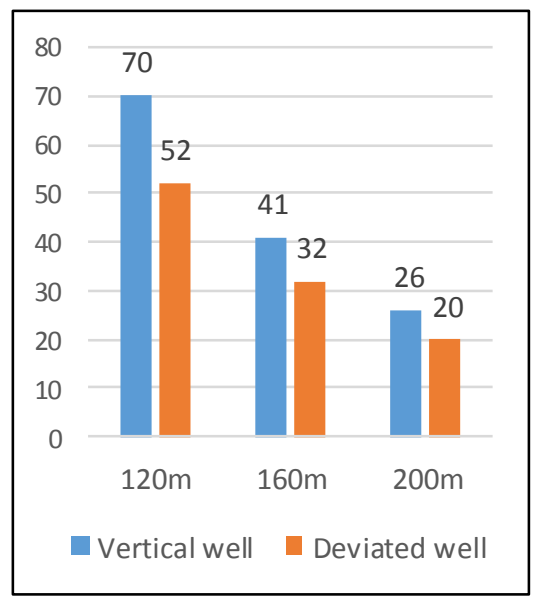

Fig. 6. Number of wells in triangular well patterns

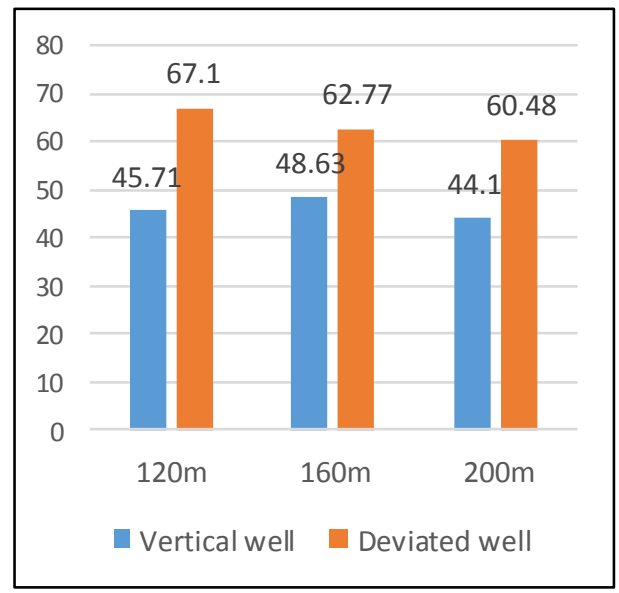

Fig. 7. Average drilling thickness of triangular well patterns

Based on the statistics of producer drilling ratio, number of producers/injectors (Fig.6) and average drilling thickness (Fig.7) for each plan, recovery factor and water consumption were predicted by using well location numerical simulation data files which were output from the software. Then, combined with optimal technical index, it was concluded that triangular pattern is superior to five-spot pattern and deviated well pattern is superior to vertical well pattern. Finally, based on economic evaluation, it was confirmed that $160 \mathrm{~m}$ is the economic limit of well spacing and Plan 8 is the optimal well pattern arrangement plan.

\section{CONCLUSIONS}

- The computer assisted well pattern optimization software is applicable to well pattern adjustment during late development of mature oil fields and layer recombination of well patterns during the secondary development.

- The computer assisted well pattern optimization software is functionally composed of automatic introduction of 3D data volume of reservoir and fluid properties, interpolation calculation of spatial grid point attributes by using layer data sheets, automatic arrangement of various areal well patterns with different well spacing and directions, adjustment and optimization of local oil and water well points, calculation of well pattern evaluation index and numerical reservoir simulation interfaces.

- With the computer assisted well pattern optimization software, multiple types of virtual well patterns can be arranged fast, and then the optimal plan with the best indicators can be selected after development indexes of each plan are calculated and predicted. In this way, the efficiency of well pattern arrangement is highly increased.

- The computer assisted well pattern optimization software has been applied to the secondary development projects of PetroChina. It is an efficient tool for assisting in decision-making for reservoir engineers to conduct layer recombination of secondary development well patterns.

\section{REFERENCES}

[1] Chen Yuanqian. Advanced reservoir engineering. Beijing: Petroleum Industry Press, 2001.

[2] Geng Zhaohua, Gao Hongyi, Guo Hongxia. Development well pattern arrangement and injection-production well pattern improvement of complex fault-block oil reservoir. Production Testing Technology, vol 21(3), 2000, pp.12-15.

[3] Xu Dongmei. Layer recombination and pattern optimization of irregular well patterns in integrity reservoirs - a case study on Layer 1-3 of the Second Member of Shahejie Formation in Lot 28, Shengtuo 3 Block. Silicon Valley. vol. 3,2012, pp.100-101.

[4] Cao Renyi, Cheng Linsong, Xue Yongchao. Well pattern optimization adjustment for low permeability oilfield. Journal of Southwest Petroleum University, vol. 29 (4),2007, pp.67-69.

[5] Liu Yujuan, Chen Jianbo. Well pattern optimization combination of high water cut oilfield: a case study for Xia-layer system of Xiaermen Oilfield. Fault-Block Oil \& Gas Field. vol.13 (3), 2006, pp.34-35.

[6] Tong Xianzhang. Characteristics and adaptability comparison between different areal water injector patterns from the point of balanced injection and production rate, International Petroleum Engineering Conference Symposium. Beijing: Petroleum Industry Press, 1982, pp.136-147.

[7] Yu Xiaodong, Wu Ying, He Lamei. Improvement and comparison of inverse distance weighted grid interpolation algorithm. Chinese Journal of Engineering Geophysics, vol. 10 (6) , 2013, pp. 900-904.

[8] Yin Hui, Wang Xinmin. Optimization scheme of well pattern based on Kriging interpolation - a case study of Liguanpu riverside source field in Hunhe of Shenyang. Global Geology, vol. 32 (4), 2013, pp.820-824.

[9] Hou Junwei, Kang Muning. Using the Command design pattern to implement the Redo/Undo function in editor. Science Technology and Engineering, vol. 4, 2010, pp.1033-1036. 